\title{
Identification of surface proteins in Enterococcus faecalis V583
}

\author{
Liv Anette Bøhle1, Tahira Riaz', Wolfgang Egge-Jacobsen², Morten Skaugen, Øyvind L Busk', \\ Vincent GH Eijsink', Geir Mathiesen ${ }^{1 *}$
}

\begin{abstract}
Background: Surface proteins are a key to a deeper understanding of the behaviour of Gram-positive bacteria interacting with the human gastro-intestinal tract. Such proteins contribute to cell wall synthesis and maintenance and are important for interactions between the bacterial cell and the human host. Since they are exposed and may play roles in pathogenicity, surface proteins are interesting targets for drug design.

Results: Using methods based on proteolytic "shaving" of bacterial cells and subsequent mass spectrometry-based protein identification, we have identified surface-located proteins in Enterococcus faecalis V583. In total 69 unique proteins were identified, few of which have been identified and characterized previously. 33 of these proteins are predicted to be cytoplasmic, whereas the other 36 are predicted to have surface locations (31) or to be secreted (5). Lipid-anchored proteins were the most dominant among the identified surface proteins. The seemingly most abundant surface proteins included a membrane protein with a potentially shedded extracellular sulfatase domain that could act on the sulfate groups in mucin and a lipid-anchored fumarate reductase that could contribute to generation of reactive oxygen species.
\end{abstract}

Conclusions: The present proteome analysis gives an experimental impression of the protein landscape on the cell surface of the pathogenic bacterium E. faecalis. The 36 identified secreted (5) and surface (31) proteins included several proteins involved in cell wall synthesis, pheromone-regulated processes, and transport of solutes, as well as proteins with unknown function. These proteins stand out as interesting targets for further investigation of the interaction between $E$. faecalis and its environment.

\section{Background}

Enterococci are versatile Gram-positive bacteria that can survive under harsh conditions. Most enterococci are non-virulent and commonly found in fermented food and in the gastrointestinal (GI) tract of humans and animals. Other strains are opportunistic pathogens that contribute in a large number of nosocomial infections worldwide [1]. The mechanism underlying the switch from a harmless microbe into a life-threatening pathogen entering the host bloodstream is not well known. It is believed that the bacteria normally are well controlled in the GI tract of healthy individuals, whereas a weakened host immune system and/or development of bacterial traits to occupy new niches may lead to

\footnotetext{
* Correspondence: geir.mathiesen@umb.no

'Department of Chemistry, Biotechnology, and Food Science, The

Norwegian University of Life Sciences, 1432 Ås, Norway Full list of author information is available at the end of the article
}

translocation to the bloodstream [2]. The past decade has shown a dramatic increase in antibiotic resistance of Enterococcus species, creating an increased need for developing new ways to combat these bacteria. To achieve this, in-depth insight in the physiology, virulence and epidemiology of enterococci is required.

Enterococcus faecalis is one of the most frequent Enterococcus species in the GI tract $[3,4]$ and accounts for at least $60 \%$ of the bacteraemia caused by Enterococcus species [1]. The genome sequence of three E. faecalis strains (V583; [5], OG1RF [6], Symbioflor 1 [7]) have been completed, and several genome projects are ongoing. In the genome sequence of $E$. faecalis V583, a vancomycin resistant clinical isolate, over a quarter of the genome consists of mobile or foreign DNA, including pathogenicity islands. The abundance of mobile elements in E. faecalis probably contributes to accumulation of virulence and drug determinants. Several studies have revealed proteins
C Biomed Central 
that contribute to the virulence of E. faecalis [8-10], but it has so far not been possible to link virulence to one or very few key gene products. Since virulence depends on the ability to colonize the GI tract and interact with host cells and proteins in the GI tract, secreted proteins and proteins located on the cell surface are thought to be important. One well-studied secreted virulence factor is cytolysin, which is toxic or lytic to bacterial and human cells $[9,11]$. Several adhesion factors facilitating binding to mucosal and epithelial surfaces have been reported [2]. In addition to involvement in adhesion, surface proteins may affect virulence in other ways, for example by involvement in cell-cell signalling [9], interactions with the host immune system, sensing environmental factors, or protection from environmental factors.

To understand the success of bacterial pathogens and their adaption to the GI tract it is important to get an impression of the repertoire of surface associated proteins. According to the LocateP database [12], which contains genome-wide predictions for the subcellular locations of bacterial proteins, 306 proteins in E. faecalis are predicted to be covalently anchored to cell surface, primarily via N-terminal or lipid anchors. Another 67 are predicted to be secreted or non-covalently attached to the surface. There is only limited experimental data supporting these predicted locations [13]. Furthermore, despite their expected importance for bacterial behaviour and impact, the function of most of the predicted surface and secreted proteins remains unknown.

In the past decade, the extracellular proteomes of several Gram-positive bacteria have been analyzed using proteomics approaches. Many of these studies employed some kind of protein extraction methods from culture supernatants and/or cell wall fractions followed by twodimensional electrophoresis and mass spectrometrybased protein identification (e.g. [14-18]). Recently, more direct and rapid methods for the "in situ" identification of surface proteins have been developed which are based on "shaving" the surface of intact bacteria with proteolytic enzymes, followed by identification of the released peptides by liquid chromatography (LC) and tandem mass spectrometry (MS/MS) [19]. An advantage of this approach is that the proteolytic enzymes will only have access to proteins that are exposed on the surface of the bacterial cell, which could limit contamination with intracellular proteins. This approach should in principle be biased towards proteins that are of particular importance for bacterial interactions with the environment. Indeed, the "shaving" approach has been applied successfully in the search for new bacterial epitopes. In a landmark study, RodriguezOrtega et al [19] identified in total 72 proteins in Streptococcus pyogenes M1_SF370 by shaving the bacterial surface with trypsin or proteinase $\mathrm{K}$. The identified proteins included known protective antigens and also revealed new promising candidate antigens for vaccine development.

In the present study, we have applied the "shaving" approach to identify the surface proteome of E. faecalis V583. Cells were treated with free trypsin or trypsin anchored to agarose beads to shave off and digest surfaceexposed proteins. Using a combination of experiments, 69 surface-located proteins were identified, including proteins assumed to be involved in pathogenicity and several proteins with unknown function. We also identified proteins that are thought to be cytoplasmic, but which tend to be found at bacterial surfaces too. We discuss the putative roles and relevance of several of the identified proteins and we compare the various approaches. The results provide a basis for the identification and further study of novel proteins putatively involved in pathogenicity and adaptability of E. faecalis V583.

\section{Methods}

\section{Culture conditions and surface shaving}

Overnight cultures of E. feacalis V583 [5] were diluted in fresh prewarmed brain heart infusion (BHI) medium (Oxoid Ltd., Hampshire, England) to an $\mathrm{OD}_{600} \sim 0.2$ and incubated at $37^{\circ} \mathrm{C}$ without agitation. The bacteria were harvested on the transition between late exponential and stationary phase $\left(\mathrm{OD}_{600} \sim 1.7\right)$ by centrifugation $\left(3000 \times \mathrm{g}, 10 \mathrm{~min}, 4^{\circ} \mathrm{C}\right)$. The cell pellet from $100 \mathrm{ml}$ of culture was washed three times with $10 \mathrm{ml}$ PBS by centrifugation $\left(3000 \times \mathrm{g}, 10 \mathrm{~min}, 4^{\circ} \mathrm{C}\right)$ and subsequently resuspended in PBS containing 40\% sucrose. Three different shaving reactions were set-up, all containing $5 \mathrm{mM}$ DTT and all with the same final concentration of cells: (1) addition of $20 \mu \mathrm{g}$ trypsin (Promega, Mannheim, Germany), (2) addition of trypsin-agarose (100 units; Invitrogen, Karlsruhe, Germany), or (3) no addition of trypsin (untreated). The samples were incubated for 1 or 2 hours at $37^{\circ} \mathrm{C}$ with shaking at $300 \mathrm{rpm}$. After incubation the cells were pelleted by centrifugation $(3000 \times$ g, $10 \mathrm{~min}$ ) and the supernatants were collected for further protein digestion with $1 \mu \mathrm{g}$ freshly added trypsin over night $(16-18 \mathrm{~h})$ at $37^{\circ} \mathrm{C}$ with agitation at $400 \mathrm{rpm}$. Cell samples taken before (i.e. after resuspending in PBS) and after the different enzymatic treatments were used to test cell viability by plating appropriate dilutions on BHI agar plates and counting of colony forming units (CFU). The overnight trypsin digestion of the supernatants was stopped by adding formic acid to a final concentration of $0.1 \%(\mathrm{v} / \mathrm{v})$. Prior to nanoLC-MS/ MS analysis, peptides were concentrated and purified in two steps using $\mathrm{C}_{18}$ Dynabeads (Invitrogen) in the first step and C18 StageTips [20] in the second step. For each treatment, samples from four biological replicates were analysed. 


\section{Nanoflow on-line liquid chromatographic MS analysis of trypticpeptides}

Reverse phase (C18) nano online liquid chromatographic MS/MS analyses of tryptic peptides were performed using a HPLC system consisting of two Agilent 1200 HPLC binary pumps (nano and capillary) with corresponding autosampler, column heater and integrated switching valve. This LC system was coupled via a nanoelectrospray ion source to a LTQ-Orbitrap mass spectrometer (Thermo Fisher Scientific, Bremen, Germany). For the analyses, the peptide solution was injected onto the $5 \times 0.3-\mathrm{mm}$ extraction column filled with Zorbax 300 SB-C18 of 5 - $\mu$ m particle size (Agilent, Waldbronn, Germany). Samples were washed with a mobile phase consisting of $97 \%$ 0.1\% formic acid \& $3 \%$ acetonitrile. The flow rate of $4 \mu \mathrm{l} / \mathrm{min}$ provided by the capillary pump. After $7 \mathrm{~min}$, the switching valve of the integrated switching valve was activated, and the peptides were eluted in the back-flush mode from the extraction column onto a $150 \times 0.075-\mathrm{mm} \mathrm{C}_{18}, 3-\mu \mathrm{m}$ resin, column (GlycproSIL C18-80Å, Glycpromass, Stove, Germany). The mobile phase consisted of acetonitrile and MS grade water, both containing $0.1 \%$ formic acid. Chromatographic separation was achieved using a binary gradient from 5 to $55 \%$ of acetonitrile in $120 \mathrm{~min}$. The flow rate of $0.2 \mu \mathrm{lmin}^{-1}$ was provided by the nanoflow pump.

Mass spectra were acquired in the positive ion mode applying a data-dependent automatic switch between survey scan and tandem mass spectra (MS/MS) acquisition. Peptide samples were analyzed by collision induced dissociation (CID) in the LTQ ion trap by acquiring one Orbitrap survey scan in the mass range of $\mathrm{m} / z$ 380-2000 followed by CID of the six most intense ions in the ion trap. The target value in the LTQ-Orbitrap was $1,000,000$ for survey scan at a resolution of 60,000 at $\mathrm{m} /$ $z 400$ using lock masses for recalibration to improve the mass accuracy of precursor ions. Fragmentation was performed with a target value of 5,000 ions. The ion selection threshold was 500 counts. Selected sequenced ions were dynamically excluded for $180 \mathrm{~s}$.

\section{MS data analysis}

Mass spectrometric data were first analyzed by generating msf files from raw MS and MS/MS spectra using the Proteome Discoverer 1.0 software (Thermo Fisher Scientific) and the database searches were then performed with an in house maintained E. faecalis V583 protein sequence database, using the SEQUEST search engine. The following criteria were applied; database decoy, true; Enzyme name, trypsin (full); Missed cleavage sites, 2; Precursor mass tolerance, 10 ppm; fragment mass tolerance: 0.6 Da; dynamic modifications: $\mathrm{N}$-term acetyl (any $\mathrm{N}$-terminus), oxidation (M), carboxymethyl $(\mathrm{C})$, deamidated $(\mathrm{N}, \mathrm{Q})$. Proteins were considered as significant hits if the following conditions were met: XCorr higher than 2.0; false discovery rate less than 5\%; identified by at least two different peptides; identified in at least two of the independent parallels by at least one peptide in each.

\section{SDS-PAGE analysis}

To visualize proteins or protein fragments that were resistant to trypsin, $20 \mu \mathrm{l}$ of the supernatant from the over-night trypsination were applied to $10 \%$ NuPAGE Novex Bis-Tris gels (Invitrogen). Only samples after two-hour incubation were studied. The gels were stained using SilverSNAP Stain for Mass Spectrometry (Pierce, Rockford, IL) following the manufacturer's procedure. After the silver staining, the gel-lane was sliced into 12 pieces, and destained using the protocol included in SilverSNAP Stain for Mass Spectrometry kit. Each gel piece was then incubated with $0.1 \mu \mathrm{g}$ trypsin in $25 \mu \mathrm{l}$ $25 \mathrm{mM}$ ammonium bicarbonate, over night at $37^{\circ} \mathrm{C}$ and $400 \mathrm{rpm}$. The trypsin reactions were stopped by adding $0.1 \%$ formic acid. The supernatants were transferred to new tubes, and the rest of the peptides were extracted from the gel pieces by incubating with $0.1 \%(\mathrm{v} / \mathrm{v})$ trifluoroacetic acid in $60 \%(\mathrm{v} / \mathrm{v})$ acetonitrile, at $37^{\circ} \mathrm{C}$, $400 \mathrm{rpm}$ for $10 \mathrm{~min}$. The extracts from three gel-pieces were pooled together (giving four samples from each treatment). The peptides were dried in a speed-vac, and rehydrated in $30 \mu \mathrm{l} 0.1 \%(\mathrm{v} / \mathrm{v})$ TFA. The peptide samples were desalted using C18 stage tips [20] prior to nanoLC-MS/MS. Proteins were considered as significant hits if the following conditions were met: XCorr higher than 2.0; false discovery rate less than 5\%; identified by at least two different peptides; identified in at least one of the three samples from each treatment.

\section{Bioinformatic analysis of protein localization}

Protein sequences used for in computo analysis of the localization of the identified proteins were extracted from the LocateP database [12] and analyzed using several bioinformatic tools. Putative $\mathrm{N}$-terminal signal sequences and cleavage sites were predicted using the Signal P 3.0 server [21] and LipoP v 1.0 [22]. The TMHMM Server v. 2.0 [23] was used to predict proteins with multiple transmembrane helices or N-terminal transmembrane anchors. Proteins with features indicating non-classical secretion were predicted using the SecretomeP 2.0 Server [24]. Domain annotations were done using Pfam [25]. After these verifications, the predicted localizations for 62 of the 69 proteins discussed below correspond to those given in the LocateP database (updated March 10, 2010). For seven proteins, we reached a different conclusion than LocateP, as described in results and discussion. 


\section{Results and discussion Protein identification}

Before carrying out the experiments, we performed extensive tests to find optimal conditions for the trypsin treatment. Most importantly, we checked the effect of incubation time (30 min to 24 hours) on cell viability. Incubation times of 2 hours or less did not lead to significant reductions in the CFU number (Additional file 1 ), whereas longer incubation times led to decreased viability (data not shown). Based on these observations, incubation times were set to one or two hours. Two hour incubations led to a higher number of identified proteins (Additional file 2). Generally, the longer incubations did not lead to an increase in the fraction of cytoplasmic proteins, confirming the absence of cell lysis during the enzymatic treatment (Additional file 2).

Intact bacterial cells were harvested and treated with either trypsin or trypsin beads (trypsin bound to agarose beads) for one or two hours. Because trypsin beads are less likely to penetrate the cell wall than free trypsin, they are more likely to only act on proteins that protrude from the cell wall. As a control, cells were incubated for one or two hours without adding trypsin. Direct analysis of released tryptic peptides led to the identification of 57 unique proteins (Table 1). Subsequent analysis of solubilized proteins and large protein fragments using SDSPAGE followed by MS-based identification (Figure 1; see Materials and Methods) led to the identification of another 12 unique proteins (Table 2). The sequences of all identified proteins were analysed using a variety of bioinformatic tools (LocateP, SignalP, Pfam, LipoP, pSORT and TMHMM) to verify or (for EF2860, EF0071, EF0123, EF0164, EF0394, EF0417 \& EF_B0004) to adjust the localization given in the LocateP database. The results are incorporated in Table $1 \& 2$ and are discussed in appropriate sections, below.

Analysis with Signal P 3.0 [21] suggested the presence of a signal peptidase I (SPase I) cleavage site in ten of the identified proteins. Four of these proteins contained a putative C-terminal LPxTG motif, whereas one additional protein (EF2860) is likely to be cell-wall anchored because it contains a putative peptidoglycan binding domain (Pfam PF12229). It should be noted that the sequences deposited in the GenBank database for two of the four LPxTG-containing proteins (EF1033 and EF2713) lack a predicted $\mathrm{N}$-terminal signal sequence. A closer look at the upstream sequences showed that the start codons probably are located 72 and 96 nucleotides upstream of the start codon suggested in the GenBank entries, for EF1033 and EF2713, respectively (Additional file 3). After this N-terminal "extension" SignalP and LipoP detected a putative SPase I cleavage site in both sequences.
Table 3 gives an overview over the predicted localizations of the 69 identified unique proteins and shows that the methods yielded a strong bias towards identifying proteins that are predicted to be covalently anchored to the cell wall or to carry lipid anchors. Several proteins were identified in more than one experiment and an overview is provided in Figure 2. Treatment with free trypsin yielded 58 proteins and treatment with trypsin beads yielded 29 proteins. Analysis of samples from untreated cells yielded 16 proteins. More detailed information concerning the numbers of proteins identified after the various treatments is provided in additional file 2 . Details of the proteomic analysis are provided in Additional file 4 and Additional file 5 containing Tables S5 and S6, respectively.

The number of proteins only identified after a "shaving" treatment amounted to 53. Nine of these were only found after treatment with trypsin beads, 38 were only found after treatment with free trypsin and six were found after both treatments (Figure 2). The 15 proteins identified with only trypsin-beads or with both trypsin and trypsin beads are likely to be exposed on the surface of the cell wall, whereas the 38 unique proteins found in the free trypsin samples fraction are probably localized deeper in the cell wall.

Of the 16 proteins identified from untreated cells, 12 were identified in all three treatments (Figure 2). While three of these are predicted to be secreted and one (EF0201) is probably cytoplasmic, the others are predicted to be attached to the bacterial surface through an anchor (five lipo-anchors and one LPxTG anchor) or cell wall binding domain (one, EF2860) or even as integral membrane protein (one, EF1264). The trypsinindependent release of these proteins may be a result of natural shedding, a phenomenon that indeed has been observed previously, in particular for lipoproteins $[15,26]$. According to a TMHMM topology prediction EF1264, annotated as membrane protein, contains five $\mathrm{N}$-terminal transmembrane helices and a huge extracellular domain with putative sulfatase activity of 523 residues (starting at amino acid 179). EF1264 was identified by many significant peptide hits spread over all treatments. Figure 3 shows that all identified peptides stem from the extracellular domain and that there is a 115 amino acid gap between the predicted integral membrane domain and the first identified tryptic fragment. Perhaps the extracellular domain is shedded after natural cleavage of EF1264. It is conceivable that such (apparently rather abundant) shedding is a physiologically relevant phenomenon since the sulfatase may remove sulphate from mucin, which would allow more easy degradation of mucin by glycosidases [27] and perhaps also could facilitate bacterial adhesion. 
Table 1 Proteins identified by LC-MS/MS analysis of tryptic fragments obtained after different treatments of intact E. faecalis V583

\begin{tabular}{|c|c|c|c|c|c|c|c|c|c|c|}
\hline \multirow[b]{2}{*}{ Gene } & \multirow[b]{2}{*}{ Pfam $^{a}$} & \multirow[b]{2}{*}{ Gene product ${ }^{b}$} & \multirow[b]{2}{*}{$\begin{array}{l}\text { Predicted } \\
\text { localization }\end{array}$} & \multicolumn{6}{|c|}{ Peptide hits $^{d}$} & \multirow[b]{2}{*}{$\begin{array}{c}\text { Total } \\
\text { cover-age } \\
\%\end{array}$} \\
\hline & & & & $\begin{array}{l}\text { Un-treated } \\
1 \text { hour }\end{array}$ & $\begin{array}{l}\text { Un-treated } \\
2 \text { hours }\end{array}$ & $\begin{array}{c}\text { Trypsin } 1 \\
\text { hour }\end{array}$ & $\begin{array}{c}\text { Trypsin } 2 \\
\text { hours }\end{array}$ & $\begin{array}{c}\text { Beads } 1 \\
\text { hour }\end{array}$ & $\begin{array}{c}\text { Beads } 2 \\
\text { hours }\end{array}$ & \\
\hline$\overline{E F}{ }_{2} B 0004^{e}$ & $\begin{array}{l}\text { Bacterial extracellular solute- } \\
\text { binding proteins, family } 5\end{array}$ & TraC protein & Cell wall & & & 2 & 2 & (1) & (1) & 13.0 \\
\hline EF0071 & Contains trehalase domain & Putative lipoprotein & $\begin{array}{l}\text { Lipid anchor SP-\|l, } \\
\text { WS-CF }\end{array}$ & & & (3) & 2 & & & 10.0 \\
\hline EF0123 & $\begin{array}{c}\text { Contains nine Clostridial hydro- } \\
\text { phobic W domain }\end{array}$ & Hypothetical protein & Secreted SP-I, AYA-LE & 5 & 2 & 9 & 7 & (1) & 4 & 23.2 \\
\hline EF0164 & & Putative lipoprotein & $\begin{array}{l}\text { Lipid anchor SP-\|l, } \\
\text { FTS-CG }\end{array}$ & 2 & 3 & 2 & 3 & & 2 & 32.3 \\
\hline EF0176 ${ }^{f}$ & Basic membrane protein & Hypothetical protein & $\begin{array}{l}\text { Lipid anchor SP-II, } \\
\text { LAA-CG }\end{array}$ & & & 3 & 5 & & 2 & 25.7 \\
\hline $\mathrm{EF} 0177^{f}$ & Basic membrane protein & Hypothetical protein & $\begin{array}{l}\text { Lipid anchor SP-II, } \\
\text { LAA-CG }\end{array}$ & & & 5 & 7 & 2 & & 32.1 \\
\hline EF01959 & & Phospho-glycerate mutase 1 & Cytoplasmic & & & 2 & (1) & & & 10.5 \\
\hline EF01999 & & 30 S ribosomal protein S7 & Cytoplasmic & & & & 2 & & & 30.1 \\
\hline $\mathrm{EF} 0200^{9}$ & & Elongation factor $G$ & Cytoplasmic & (1) & & 7 & 7 & & & 22.4 \\
\hline $\mathrm{EF} 0201^{\mathrm{fg}}$ & & Elongation factor Tu & Cytoplasmic & (1) & 2 & 11 & 8 & 5 & 4 & 47.1 \\
\hline EF0205 & & $30 \mathrm{~S}$ ribosomal protein $\mathrm{S} 10$ & Cytoplasmic & & & 2 & & & (1) & 29.4 \\
\hline EF0206 & & $50 S$ ribosomal protein L3 & Cytoplasmic & & & 2 & 5 & & & 23.4 \\
\hline $\mathrm{EF} 0207^{9}$ & & $50 S$ ribosomal protein $L 4$ & Cytoplasmic & & & (1) & 2 & & & 15.9 \\
\hline EF0211 & & 50 S ribosomal protein L22 & Cytoplasmic & (1) & 2 & & 2 & (1) & (1) & 17.4 \\
\hline EF0218 & & $50 S$ ribosomal protein $L 5$ & Cytoplasmic & & & (1) & 3 & & & 21.2 \\
\hline $\mathrm{EF} 0221^{\mathrm{g}}$ & & 50 S ribosomal protein L6 & Cytoplasmic & & & (1) & 3 & & & 27.0 \\
\hline EF0223 & & 50 S ribosomal protein L18 & Cytoplasmic & & & (1) & 2 & & & 39.0 \\
\hline EF0226 & & $50 S$ ribosomal protein L15 & Cytoplasmic & (1) & (2) & 2 & (1) & (1) & (1) & 21.2 \\
\hline EF0228 & & Adenylate kinase & Cytoplasmic & & & 2 & 2 & & & 19.4 \\
\hline $\mathrm{EF} 0234^{\mathrm{g}}$ & & 50 ribosomal protein L17 & Cytoplasmic & & & 2 & (1) & & & 26.0 \\
\hline EF0304 & - & Putative lipoprotein & $\begin{array}{l}\text { Lipid anchor SP-II, } \\
\text { LSA-CS }\end{array}$ & & & (1) & 2 & & 2 & 20.5 \\
\hline EF0394 & $\begin{array}{c}\text { Cysteine-rich secretory protein } \\
\text { family }\end{array}$ & Secreted antigen, putative & Secreted SP-I, ALA-DN & 2 & & & & 3 & (1) & 17.8 \\
\hline EF0417 & - & Hypothetical protein & Secreted SP-I, VNA-LN & 3 & 2 & 4 & 4 & & 3 & 11.2 \\
\hline EF0502 & - & Hypothetical protein & $\begin{array}{l}\text { Multiple } \\
\text { transmembrane } \\
\text { proteins }\end{array}$ & & & & & & 2 & 7.9 \\
\hline EF0633 & & tyrosyl-tRNA synthetase & Cytoplasmic & & & & 2 & & & 6.9 \\
\hline $\mathrm{EF} 0685^{\mathrm{f}}$ & & Rotamase family protein & $\begin{array}{l}\text { Lipid anchor SP-\|l, } \\
\text { LAA-CS }\end{array}$ & & & & 2 & & & 10.8 \\
\hline EF0737 & & Amidase & $\mathrm{N}$-terminal anchor & & & & 2 & & & 6.8 \\
\hline
\end{tabular}


Table 1 Proteins identified by LC-MS/MS analysis of tryptic fragments obtained after different treatments of intact E. faecalis V583 (Continued)

\begin{tabular}{|c|c|c|c|c|c|c|c|c|c|c|}
\hline${\mathrm{EF} 0907^{f}}$ & - & $\begin{array}{l}\text { Peptide ABC transporter peptide- } \\
\text { binding protein }\end{array}$ & $\begin{array}{c}\text { Lipid anchor SP-II, LAA- } \\
\text { CG }\end{array}$ & & & & 2 & & & 16.4 \\
\hline EF0916 & & 50 S ribosomal protein L20 & Cytoplasmic & $(1)$ & $(1)$ & 2 & & & & 27.7 \\
\hline EF0970 & & $50 S$ ribosomal protein L27 & Cytoplasmic & & & 2 & 2 & & & 34.7 \\
\hline EF0991 & & Penicillin-binding protein C & $\mathrm{N}$-terminal anchor & & & $(1)$ & 2 & & & 11.2 \\
\hline EF1033 & & Lipoamidase & $\begin{array}{l}\text { Cell wall anchored } \\
\text { LPXTG SP-I, AQE-SI }\end{array}$ & & & 2 & 2 & & & 4.7 \\
\hline EF1046 & & Pyruvate kinase & Cytoplasmic & $(2)$ & & $(2)$ & 2 & & & 11.6 \\
\hline EF11679 & & Fructose-bisphosphate aldolase & Cytoplasmic & $(1)$ & $(2)$ & 2 & 4 & 3 & (1) & 30.8 \\
\hline EF1264 & & $\begin{array}{l}\text { Sulfatase domain-containing } \\
\text { protein }\end{array}$ & $\begin{array}{l}\text { Multiple trans- } \\
\text { membrane proteins }\end{array}$ & 2 & & 10 & 11 & (1) & 5 & 29.8 \\
\hline EF1308 $8^{\mathrm{fg}}$ & & Dnak protein & Cytoplasmic & (1) & & 2 & 3 & & & 23.7 \\
\hline EF1319 & - & Hypothetical protein & N-terminal anchor & & & $(1)$ & 3 & & & 23.3 \\
\hline EF1379 & & Alanyl-tRNA synthetase & Cytoplasmic & & & & & 2 & & 3.3 \\
\hline EF1420 & - & Hypothetical protein & $\begin{array}{l}\text { Lipid anchor SP-II, MTA- } \\
\text { CS }\end{array}$ & & & 2 & $(1)$ & & & 15.6 \\
\hline EF1523 & - & Hypothetical protein & Cytoplasmic & & & (1) & 3 & & & 6.4 \\
\hline EF1613 fg & & Formate acetyltransferase & Cytoplasmic & & & 3 & $(2)$ & & & 13.4 \\
\hline EF1818 ${ }^{f}$ & & Coccolysin & Secreted SP-I, VAA-EE & 8 & 3 & 8 & 5 & (1) & 2 & 45.1 \\
\hline EF1898 & & 50 S ribosomal protein L19 & Cytoplasmic & & & $(1)$ & 2 & & & 30.4 \\
\hline EF1961 $1^{\mathrm{fg}}$ & & Enolase & Cytoplasmic & & & 2 & 4 & $(1)$ & & 25.7 \\
\hline EF1964 $4^{\mathrm{fg}}$ & & $\begin{array}{l}\text { Glycer-aldehyde-3-phosphate } \\
\text { dehydrogenase (GAPDH) }\end{array}$ & Cytoplasmic & & & 3 & 8 & & & 36.0 \\
\hline EF2144 & - & Putative lipoprotein & $\begin{array}{l}\text { Lipid anchor SP-II LTA- } \\
\text { CS }\end{array}$ & $(1)$ & 2 & $(1)$ & 2 & & & 22.4 \\
\hline EF2174 & Glycosyl hydrolases family 25 & Hypothetical protein & Secreted SP-I, ASG-EE & & & & 3 & & & 4.5 \\
\hline $\mathrm{EF} 2398^{\mathrm{g}}$ & & 30 S ribosomal protein $\mathrm{S} 2$ & Cytoplasmic & $(1)$ & & 2 & 4 & 2 & (1) & 19.2 \\
\hline EF2556 & & $\begin{array}{c}\text { Fumarate reductase flavoprotein } \\
\text { subunit }\end{array}$ & $\begin{array}{l}\text { Lipid anchor SP-\|l, ATG- } \\
\text { CT }\end{array}$ & 40 & 39 & 40 & 41 & 22 & 37 & 79.2 \\
\hline EF2718 ${ }^{\mathrm{ge}}$ & & 50 S ribosomal protein L1 & Cytoplasmic & & & 2 & 2 & & & 24.0 \\
\hline $\mathrm{EF} 2746$ & & DltD protein & N-terminal anchor & (1) & 2 & 2 & 3 & (1) & 2 & 10.4 \\
\hline
\end{tabular}


Table 1 Proteins identified by LC-MS/MS analysis of tryptic fragments obtained after different treatments of intact E. faecalis V583 (Continued)

\begin{tabular}{|c|c|c|c|c|c|c|c|c|c|c|}
\hline$\overline{E F} 2860^{f}$ & & $\begin{array}{c}\text { YkuD putative, peptido-glycan } \\
\text { binding domain }\end{array}$ & Cell wall, SP-I VYF-QS, & 2 & 6 & 5 & 9 & (1) & 7 & 36.3 \\
\hline EF2864 & - & Hypothetical protein & $\begin{array}{l}\text { Lipid anchor SP-II, } \\
\text { LTA-CR }\end{array}$ & 2 & 2 & 3 & 4 & 2 & 2 & 25.7 \\
\hline EF2925 9 & & $\begin{array}{c}\text { Cold-shock domain-contain } \\
\text { protein }\end{array}$ & Cytoplasmic & (1) & 2 & & & (1) & 2 & 45.5 \\
\hline$E F 3041^{f}$ & & Pheromone binding protein & $\begin{array}{l}\text { Lipid anchor SP-II, } \\
\text { LAA-CG }\end{array}$ & 2 & 3 & 2 & 7 & & 2 & 24.3 \\
\hline $\mathrm{EF} 3256^{\mathrm{f}}$ & & $\begin{array}{c}\text { Pheromone CAD1 precursor } \\
\text { lipoprotein }\end{array}$ & $\begin{array}{l}\text { Lipid anchor SP-II, } \\
\text { LAA-CG }\end{array}$ & & & (1) & 2 & & & 19.4 \\
\hline EFA0003 & & TraC protein & $\begin{array}{l}\text { Lipid anchor SP-II, } \\
\text { LGA-CN }\end{array}$ & & & & 2 & & & 9.4 \\
\hline
\end{tabular}

Further details on the Sequest-based protein identification process are provided in the Materials and Methods section and in Table S5 (Additional file 4).

aSignificant hits (or absence thereof, indicated by -) obtained after searches in Pfam [25] for putative and hypothetical proteins.

${ }^{\mathrm{b}}$ All data extracted from the LocateP database [12] with two exceptions: EF1033 (annotated as 6-aminohexanoate-cyclic-dimer hydrolase; annotated as putative, in LocateP) and EF2860 annotated as ErfK/YbiS/YcfS/ YnhG family protein; annotated as putative, in LocateP).

CPredicted localization and potential cleavage site. Localization is based on LocateP annotations, with seven exceptions (for Tables 1 and 2 in total) that are all explicitly mentioned in the text. See also Table 3.

${ }^{\mathrm{d}}$ The column shows the number of peptide hits from four biological replicates. Protein identifications were considered significant using the criteria described in Materials and Methods. One criterium was the

detection of at least two different peptides; another the detection of peptides in at least two independent parallels; these criteria are met for all listed proteins. Putative, non-significant additional identifications of these proteins (based on just one peptide and/or on just one parallel) are indicated in parentheses.

"SecretomeP value $>0.5$; this means that the protein is predicted to be secreted via a "non-classical" pathway.

${ }^{f}$ Proteins that have been identified as being localised on the surface in a previous study of E. faecelis JH2-2 [13].

${ }^{9}$ Cytoplasmic proteins that have been identified in other studies of the surface proteomes of Gram-positive bacteria. See text for references. 


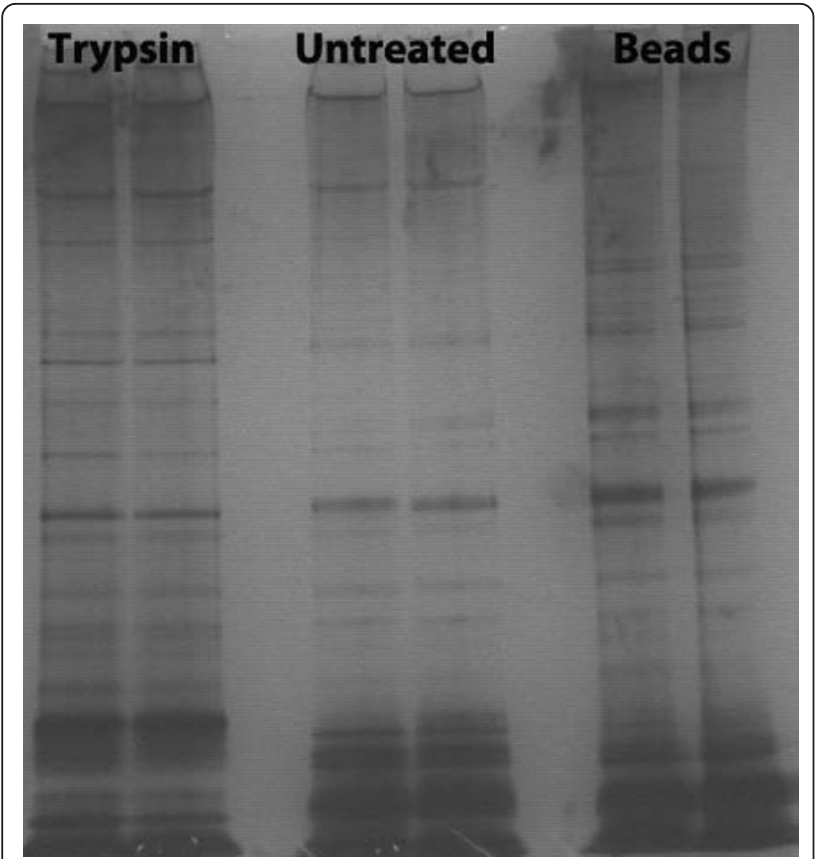

Figure 1 SDS-PAGE analysis of the supernatants obtained after treating intact cells with trypsin; see materials and methods for details. The gel shows the results from cells treated with trypsin, cells treated with trypsin beads and a control sample ("untreated") where no trypsin was added. Samples sizes represent approximately the same amount of cells in all lanes.

Table 3 Summary of the identified proteins grouped according to predicted localization

\begin{tabular}{|c|c|c|c|}
\hline $\begin{array}{l}\text { Predicated } \\
\text { localization }^{a}\end{array}$ & $\begin{array}{l}\text { Number of } \\
\text { identified unique } \\
\text { proteins }\end{array}$ & $\begin{array}{l}\text { Number in the } \\
\text { E. faecalis V583 } \\
\text { genome }^{b}\end{array}$ & $\begin{array}{l}\text { Percent } \\
\text { identified }\end{array}$ \\
\hline Cytoplasmic & 33 & 2303 & 1.4 \\
\hline Membrane ${ }^{c}$ & 3 & 588 & 0.5 \\
\hline Lipid anchor & 17 & 74 & 23.0 \\
\hline $\begin{array}{l}\text { N-terminal } \\
\text { anchor }\end{array}$ & 5 & 190 & 2.6 \\
\hline $\begin{array}{l}\text { LPXTG } \\
\text { proteins }\end{array}$ & 4 & 38 & 10.5 \\
\hline $\begin{array}{l}\text { Cell wall } \\
\text { associated }\end{array}$ & 2 & $N D^{d}$ & $N D^{d}$ \\
\hline Secreted & 5 & 59 & 8.5 \\
\hline $\begin{array}{l}\text { C-terminal } \\
\text { anchor }\end{array}$ & 0 & 4 & 0 \\
\hline $\begin{array}{l}\text { Secreted via } \\
\text { minor } \\
\text { pathway }\end{array}$ & 0 & 8 & 0 \\
\hline Sum & 69 & 3264 & 2.1 \\
\hline
\end{tabular}

${ }^{a}$ Localization data are from LocateP (Zhou et al., 2008), with the seven corrections described in the text. According to Locate $\mathrm{P}$, the numbers of identified cytoplasmic, lipid anchor, N-terminal anchor, cell wall associated and secreted proteins.

b Data from the LocateP database.

c Containing multiple transmembrane helices.

${ }^{d}$ Not detected (ND), LocateP only predicts cell wall proteins with LPxTG motifs.

\section{Cytoplasmic proteins}

According to the LocateP database 34 of the 69 identified proteins lack an N-terminal signal sequence and are therefore predicted to be cytoplasmic proteins. All these proteins were analysed using PSORTb v.3.0 [28] and the SecretomeP (SecP) 2.0 Server [24,29]. SecP predict proteins that are putatively secreted without having a detectable N-terminal signal sequence, i.e. by "non-classical secretion". Analysis with SecP indicated that four of the proteins predicted to be cytoplasmic (EF0970, EF1523, EF2718 and EF_B0004) may follow non-classical secretion. PSORTb predicted EF_B0004 (TraC protein) to be a cell wall protein and Pfam gave a significant hit against "Bacterial extracellular solute-binding proteins, family 5" (PF00496). It has been shown that TraC proteins play a role as surface pheromone receptor and are thereby involved in the regulation of the conjugation process [30,31]. Therefore, EF_B0004 was classified as a cell wall protein in this study. The other three proteins were retained as cytoplasmic, despite the fact that PSORTb predicted EF0970 (ribosomal protein L27) to have an extracellular location.

Identification of cytoplasmic proteins at extracellular locations is not unusual and at least 20 of the 33 proteins found in this study have been identified in previous studies of the secretomes or surface proteomes of Grampositive bacteria (Tables 1 and 2) [13,18,26,32-36]. The majority of the identified cytoplasmic proteins were unique to the trypsin fraction and/or the beads fraction, indicating that these proteins bind to the cell envelope and need to be "shaved" from the surface, despite the lack of known binding motifs or domains. Many of the identified cytoplasmic proteins are highly abundant proteins like ribosomal proteins (Rbps; more than $20 \%$ of all identified proteins), EF-Tu/G, GADPH and chaperones, which suggests that cell lysis rather than an unknown active secretion process determines their extracellular presence. While the cell viability checks described above indicate that cell lysis due to the trypsin treatment is unlikely, it is conceivable that cell lysis in the cell culture prior to the trypsin treatment may have released intracellular proteins that somehow have re-associated with the cell envelope and escaped proteolytic degradation [26,37].

While cytoplasmic proteins found in studies such as the present generally must be considered contaminants, there have been speculations in the literature that some of these actually may have extracellular functions. One example is Rbp L7/L12 (EF2715) which has been identified at the surface of several Gram positive bacteria $[19,26,34,35,38]$. We found Rbp L7/L12 in the beads fraction only and this implies an exposed localization, similar to the localization suggested in B. subtilis [26]. Bacterial Rbp L7/L12 has immunogenic properties in humans $[38,39]$ and is being explored as candidate 
Table 2 Additional proteins identified using the SDS-PAGE approach after different treatments

\begin{tabular}{|c|c|c|c|c|c|c|c|}
\hline \multirow[b]{2}{*}{ Gene } & \multirow[b]{2}{*}{$\mathrm{Pfam}^{\mathrm{a}}$} & \multirow[b]{2}{*}{ Gene products $^{\mathrm{b}}$} & \multirow[b]{2}{*}{ Predicted localization ${ }^{c}$} & \multicolumn{3}{|c|}{ Peptide hits $^{d}$} & \multirow[b]{2}{*}{$\begin{array}{l}\text { Coverage } \\
\%\end{array}$} \\
\hline & & & & $\begin{array}{l}\text { Untreated } \\
2 \text { hours }\end{array}$ & $\begin{array}{l}\text { Trypsin } \\
2 \text { hours }\end{array}$ & $\begin{array}{c}\text { Beads } \\
2 \text { hours }\end{array}$ & \\
\hline EF0517 & & 2-dehydropantoate 2-reductase & Cytoplasmic & & & 2 & 13.1 \\
\hline EF0968 & & 50 S ribosomal protein L21 & Cytoplasmic & & & 2 & 35.3 \\
\hline EF2221 & & $\begin{array}{l}\text { ABC transporter. substrate-binding } \\
\text { protein }\end{array}$ & $\begin{array}{l}\text { Lipid anchor SP-II, } \\
\text { LSA-CG }\end{array}$ & & & 2 & 8.8 \\
\hline EF2224 & $\begin{array}{l}\text { Four DUF11 } \\
\text { repeats }\end{array}$ & $\begin{array}{c}\text { Cell wall surface anchor family } \\
\text { protein }\end{array}$ & $\begin{array}{l}\text { Cell wall, LPXTG, SP-I, } \\
\text { MNA-FA }\end{array}$ & & & 2 & 1.4 \\
\hline EF2633 & & Chaperonin. GroEL & Cytoplasmic & & & 4 & 9.2 \\
\hline EF2713 & $\begin{array}{l}\text { Gram positive } \\
\text { anchor }\end{array}$ & $\begin{array}{c}\text { Cell wall surface anchor family } \\
\text { protein }\end{array}$ & $\begin{array}{c}\text { Cell wall, LPXTG, SP-l } \\
\text { WWA-ED }\end{array}$ & & 2 & & 9.4 \\
\hline$E F 2715^{f}$ & & Ribosomal protein L7/L12 & Cytoplasmic & & & 2 & 29.5 \\
\hline $\mathrm{EF} 2857^{\mathrm{e}}$ & & Penicillin-binding protein 2B & N-terminal anchor & & & 3 & 4.8 \\
\hline EF2903 & & $\begin{array}{c}\text { ABC transporter, substrate-binding } \\
\text { protein }\end{array}$ & $\begin{array}{l}\text { Lipid anchor SP-II, } \\
\text { LGA-CG }\end{array}$ & & 6 & 2 & 20.2 \\
\hline EF3106 & & $\begin{array}{l}\text { Peptide ABC transporter. peptide- } \\
\text { binding protein }\end{array}$ & $\begin{array}{l}\text { Lipid anchor SP-II, } \\
\text { LAA-CG }\end{array}$ & & 2 & & 3.4 \\
\hline EF3257 & & $\begin{array}{l}\text { Pyridine nucleotide-disulfide family } \\
\text { oxidoreductase }\end{array}$ & $\begin{array}{l}\text { Multiple transmembrane } \\
\text { proteins }\end{array}$ & & 2 & & 7.3 \\
\hline EFA0052 & & Surface exclusion protein Sea1 & $\begin{array}{c}\text { Cell wall LPXTG SP-1, } \\
\text { VQA-AE }\end{array}$ & 2 & 2 & 2 & 6.3 \\
\hline
\end{tabular}

The gel approach yielded 25 unique proteins in total but only 12 of these were novel compared to the list of Table 1; see Additional file 2 for more details. Further details on the Sequest-based protein identification process are provided in the Materials and Methods section and in Table S6 (Additional file 5).

${ }^{a}$ Significant hits obtained after searches in Pfam [25] for putative and hypothetical proteins.

${ }^{b}$ Data extracted from the LocateP database [12].

'Predicted localization and potential cleavage site. Localization is based on LocateP annotations, with seven exceptions (for Tables 1 and 2 in total) that are all explicitly mentioned in the text. See also Table 3.

${ }^{\mathrm{d}}$ Number of peptide hits in each of the three treatments. Protein identifications were considered significant using the criteria described in Materials and Methods. Proteins were only considered a significant hit if at least two unique peptides were found.

e Proteins that have been identified as being localised on the surface in a previous study of E. faecelis JH2-2 [13].

${ }^{f}$ Cytoplasmic proteins that have been identified in other studies of the surface proteomes of Gram-positive bacteria. See text for references.

antigen for vaccine purposes [40,41]. Recent data showed that exposure of bacterial Rbp L7/L12 is a risk factor for colorectal cancer and stimulates progression of adenomas into carcinomas [42]. There has also been some speculation about possible adhesive roles of extracellular EF-Tu, DnaK, enolase and GAPDH, all identified in the present study and in a recent study of the laboratory strain Enterococcus faecalis JH2-2 [13], since these proteins bind strongly to human plasminogen [32].

\section{Secreted proteins}

Proteins were annotated as being secreted to the culture medium if the bioinformatic analyses showed the presence of a SPaseI cleavage site and did not reveal any sequence or domain known to be involved in covalent or non-covalent binding to the cell wall. Only five such proteins were identified indicating that few secreted proteins are closely associated to the microbe. Three of the secreted proteins (EF0123, EF0394, EF0417) are annotated as N-terminally anchored in the LocateP database. It is, however, not easy to differentiate between secreted proteins with processed signal peptides and proteins that retain their signal peptides as N-terminal membrane anchors [12]. The Signal P server predicted all three proteins to contain a unique cleavage site, when using both algorithms in the program. All three were detected even without trypsin treatment, suggesting a loose association with the cell envelope. Taken together, we conclude that EF0123, EF0394 and EF0417 are secreted proteins.

EF2174 was detected after trypsin treatment only and putatively encodes a glycoside hydrolase belonging to family GH25 [43]. This family comprises enzymes with lysozyme activity that are thought to be involved in peptidoglycan remodelling during cell division [44].

The well known secreted metalloprotease coccolysin, a gelatinase (EF1818; GelE) was identified after all treatments (Table 1), indicating that GelE is loosely associated to the cell surface. Coccolysin is known to be associated with virulence and is capable of degrading cellular tissues during infection, cleaving substrates such as haemoglobin, collagen and fibrin $[45,46]$. There are also indications that GelE is required for biofilm formation [47].

\section{Proteins on the surface}

Among the 31 non-secreted non-cytoplasmic proteins found in this study (Table 3), three are annotated as 




Figure 2 Overview over the identifcation of 69 surface-located proteins using various treatments of enterococcal cells. The putative cellular localizations of the identified proteins, as provided in Table 3 are indicated. In total 58, 16 and 29 proteins were identified in the trypsin, untreated and beads samples, respectively. Note that this figure combines the data from the one and two hour treatments and includes the data from both the direct LC-MS/MS analysis and the SDS-PAGE-based approach. More details about the numbers of identified proteins in the various experiments are provided in Additional file 2. Proteins containing multiple transmembrane helices are indicated by "Membrane"; proteins indicated by "Cell Wall" include 4 proteins with LPXTG anchors and two proteins containing domains known to display cell wall binding affinity.

integral membrane proteins. We identified only $0.5 \%$ of the predicted transmembrane proteins in the genome of E. faecalis V583 (Table 3). Such low numbers of identified transmembrane proteins are not unusual $[19,26,37,48]$ and are likely to be due to limited accessibility of the proteins and/or a limited ability of trypsin to penetrate the cell wall. One of these transmembrane proteins, the sulfatase (EF1264), was detected by many peptides after all treatments (see above and Figure 3). The other two were only detected after trypsin treatment and only by a minimal number of peptides. EF0502 is a 781-residue hypothetical protein which according to topology predictions contains several extracellular domains. Both detected peptides are predicted to have an extracellular location. EF3257 is a 648-residue oxidoreductase belonging to the pyridine nucleotide-disulfide family with probably only two transmembrane helices and a large extracellular domain. Both detected peptides stem from extracellular domains.

Five identified proteins are thought to be $\mathrm{N}$-terminally anchored to the cell membrane via a Sec-type signal peptide that is not cleaved off during secretion.
Relatively few such proteins were identified (Table 3), suggesting that they are expressed at low levels or that they generally have low accessibility for trypsin. Among these proteins are two penicillin-binding proteins (EF2857 \& EF0991), one amidase (EF0737) and one protein of unknown function (EF1319). EF2857 and EF0991 are class $\mathrm{B}$ penicillin binding proteins (PBP), which are transpeptidases involved in the final stage of cell wall synthesis [49]. E. faecalis has three class B PBPs that have low affinity for $\beta$-lactams and can take over the transpeptidase activity of more high affinity PBPs when these are inhibited by antibiotics [50]. We also identified a L,D-transpeptidase (EF2860; YkuD domain), in all treatments and with a high number of peptide hits, indicating that this protein is abundant at the surface of V583. Studies on E. faecium have indicated that L,Dtranspeptidase activity may represent another way to bypass inhibition of PBPs [51,52].

The fifth protein, DltD (EF2746), is also involved in the biosynthesis of surface structures. The dltD gene is part of an operon consisting four genes (dltA-dltD) whose gene products are all necessary to incorporate D-alanyl residues into lipoteichoic acids (LTA) [53,54]. It has previously been shown that disruption of genes in the dlt operon of E. faecalis lead to diminished adhesion to eukaryotic cells and less biofilm formation, indicating that the $d l t$ operon is involved in pathogenicity [55]. Interestingly, it is not fully established whether the $\mathrm{N}$-terminal anchor tethers DltD to the inner or outer leaflet of the membrane $[53,56]$. The fact that DltD was detected after all types of treatments may be taken to suggest that the protein is attached to the outer leaflet, as one would expect for proteins using a Sec-type signal peptide as membrane anchor.

Of the four proteins containing a putative LPxTG anchor, two (EF2224 \& EF2713) have unknown functions. EF2713 is up-regulated when E. faecalis V583 is grown in the presence of blood [57], indicating a putative role of this protein in infection processes. The LPxTG anchor protein EF2224 contains five copies of a so-called DUF11 repeat with unknown function and is a putative member of the MSCRAMM (mirobial surface component recognizing adhesive matrix molecules) family of proteins [58]. These proteins contain tandemly repeated immunoglobulin-like folds as observed for staphylococcal adhesins. The E. faecalis V583 genome contains seventeen proteins belonging to the MSCRAMM family [59]. Interestingly, EF2224 is highly expressed during the infection process in humans [59].

The LPxTG anchor protein EF1033 is a lipoamidase (Lpa) cleaving lipoic acids from lipoylated molecules [60,61]. EF1033 was only detected after trypsin treatment, indicative of covalent cell wall attachment. Lipoic acid is an essential sulphur containing cofactor of several 


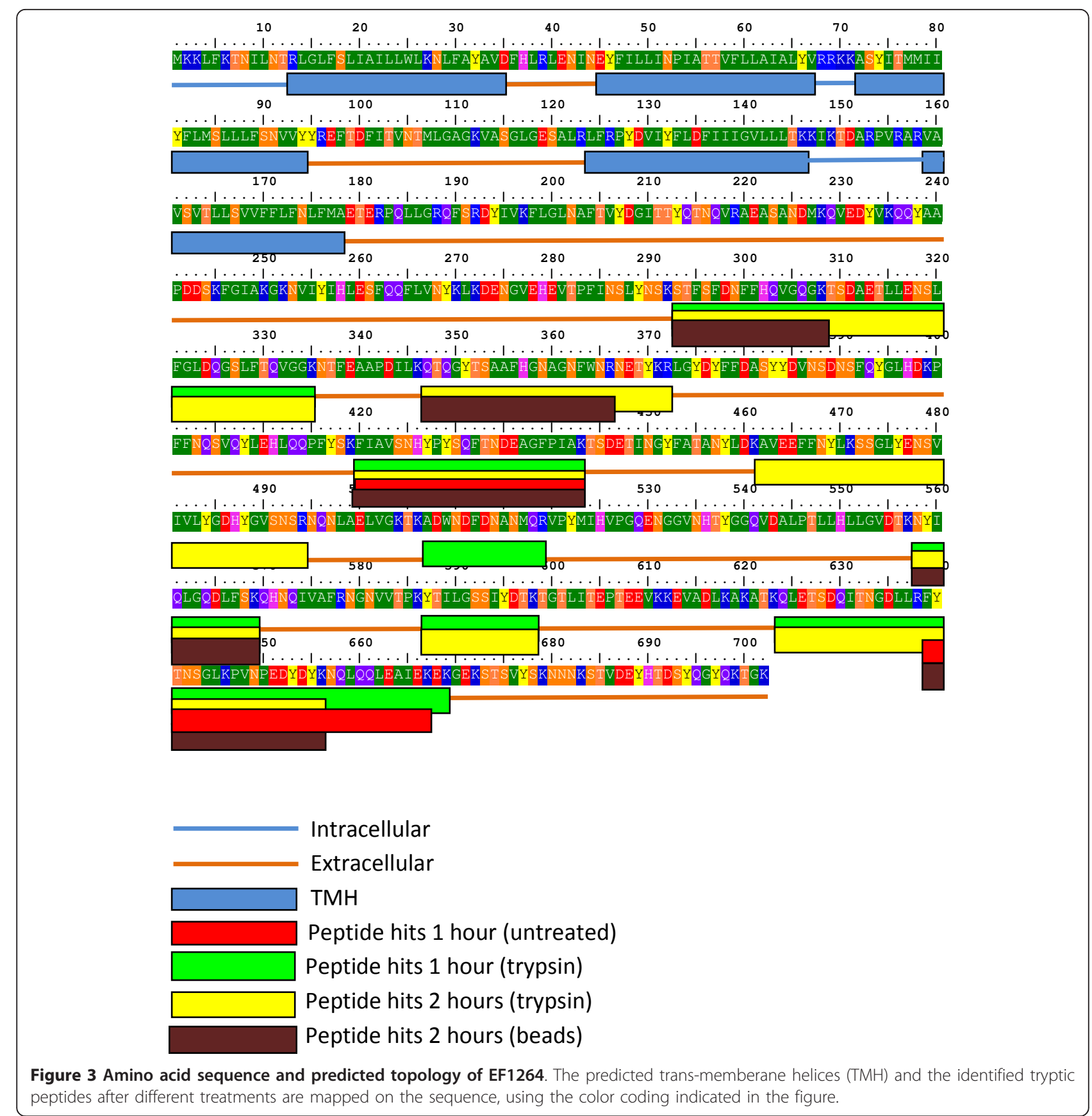

enzymes. Interestingly, so far, E. faecalis is the only bacterial species in which Lpa activity has been detected [61]. Jiang and Cronan [61] speculate that the Lpa is a cytoplasmic salvage enzyme, but our experimental and bioinformatic results indicate that the enzyme is a cell wall anchored protein. Most likely, Lpa recruits its substrates from the environment, such as the GI tract.

The fourth LPxTG protein is the plasmid encoded surface exclusion factor Sea1 (EFA0052) which is involved in the regulation of sex pheromone-controlled conjugation [62].
EF2860 is linked to the cell wall by a peptidoglucan binding domain and encodes a cell wall modifying transpeptidase homologous with YkuD from Bacillus subtilis. This protein was found after all three treatments and identified with relatively many peptide hits (Table 1 ), indicating that EF2860 is abundant on the surface and may show a relatively large extent of shedding. This protein may contribute to the antibiotic resistance of $E$. faecalis, as discussed above.

The most populated group of proteins identified in this study are the lipoproteins, of which 17 were 
detected, representing 23\% of the lipoproteins putatively encoded on the E. faecalis genome (Table 3). Twelve of these were detected only after a "shaving" treatment. Seven of the detected lipoproteins are proteins with no predicted function. Two of these unknown lipoproteins (EF0176 \& EF0177) are located on the same operon, share $70 \%$ sequence identity, and contain a "Basic membrane protein" domain (PF02608) belonging to Clan CL0144 in the Pfam database. This clan consists of proteins that are involved in chemotaxis and membrane transport of sugars as well as outer membrane proteins that are known for their antigenicity in pathogenic bacteria. Both proteins are homologous with a CD4+ Tcell-stimulating antigen in Listeria [63]. One of the other proteins with unknown function, EF0164, is annotated as N-terminally anchored in the LocateP database, but is classified as a lipoanchored protein on the basis of our analyses with LipoP.

Of the ten lipoproteins with predicted functions, four lipoproteins resemble the substrate-binding domains of multi-component $\mathrm{ABC}$ transporters for the import of peptides (EF0907, EF3106) or sugars (EF2221, EF2903). Three proteins (EF3041, EF3256, EFA0003) are involved in pheromone-regulated processes that include conjugation [31], adding to the two cell wall associated proteins involved in these processes that are discussed above (EFB0004 \& EFA0052). EF0071 seems to encode a glycoside hydrolase belonging to clan GH-G in the CAZy database. The protein is classified as N-terminally anchored in the LocateP database, but our analyses with the LipoP program clearly indicated that EF0071 is a lipoanchored protein. EF0685 belongs to the rotamase family and is thus likely to be involved in extracellular protein folding, possibly by exerting prolyl-peptidyl isomerase activity.

The final lipo-anchored protein is EF2556, fumarate reductase, which was detected by remarkably large numbers of peptides after all treatments (Table 1). E. faecalis is one of few bacteria that produces substantial amounts of extracellular superoxide. Fumarate reductase is likely to be involved in superoxide production and may thus be an important source of oxidative stress for the host [64]. It has been demonstrated that the superoxide from E. faecalis promotes chromosomal instability in mammalian cells and that this can lead to colorectal cancer $[65,66]$.

\section{Conclusions}

In recent years, several analyses of bacterial surface proteomes have been described. Despite the improvements in the mass spectrometry methods, the numbers of identified proteins are normally in the order of $30-80$, meaning that only a minority of the putative surfacelocated proteins is being found. In this type of studies, it is common to find a significant fraction of proteins that are thought to be cytoplasmic and there is some evidence that this is not just the result from artefacts such as cell lysis. We show that the large majority of the identified cytoplasmic proteins are only found after treatment with trypsin. This is an important observation, since it shows that these proteins bind tightly to the cell envelope.

In a recent published proteomics-based analysis 38 proteins were identified on the surface of E. faecalis JH2-2 [13]. Seventeen of these proteins were found after using a method similar to the one used here (i.e. surface shaving with trypsin) and seven of these were also found in the present study (EF0177, EF0201, EF0907, EF1613, EF1964, EF2556 and EF3256). Disparities between this type of studies may be due to many factors, e.g. differences between the strains and growth conditions or differences in the confidence of protein identification. Benachour et al [13] allowed protein identification on the basis of only one peptide hit, while we required at least two peptides for confident identification. Large inter-strain variation has been observed in several previous studies, both for secreted proteins and for proteins detected by a trypsin-shaving approach $[34,67,68]$.

In conclusion, our studies reveal 69 surface-located proteins in E. faecalis V583 with varying roles in bacterial behaviour. Several of the identified proteins are involved in cell wall synthesis and maintenance as well as in cellcell communication and seem interesting targets for drug design. We detected only a few proteins with known or conceivable functions in adhesion, but such proteins may be among the many identified proteins with unknown function. Clearly, the identified proteins with unknown function stand out as targets for more in-depth investigations and several of these are currently subjected to knock-out studies in our laboratory.

\section{Additional material}

Additional file 1: Figure S1: Control of viability of the cells before and after incubation for one or two hours with trypsin, trypsin beads or without any enzyme.

Additional file 2: Table S1-S4: Number of identified proteins in each treatment PDF

Additional file 3: Figure S2: Nucleotide and amino acid sequences of EF1033 and EF2713 after adjustment of the start codon.

Additional file 4: Table S5: Proteome data of the proteins identified by LC-MS analysis after different treatments.

Additional file 5: Table S6: Proteome data of the proteins identified using the SDS-PAGE approach after different treatments.

\section{Acknowledgements}

We thank Dr. Manuel Josè Rodriquez Ortega for helpful discussions. This work was funded by grants 159058, 183627 and 183637 and from The Norwegian Research Council. 


\section{Author details}

'Department of Chemistry, Biotechnology, and Food Science, The Norwegian University of Life Sciences, 1432 Ås, Norway. ${ }^{2}$ Department of Molecular Biosciences, Glyconor Mass Spectrometry, University of Oslo, 0316 Oslo, Norway.

\section{Authors' contributions}

$L A B, G M, T R$ and VE developed the initial concept for this study. All authors participated in experimental design and coordination of the study. $L A B$ and TR carried out shaving experiments. MS, WEJ and ØB contributed to the experimental design of the mass spectrometry experiments. $L A B, T R, W E J$ carried out the LC-MS/MS analysis. GM and LAB did the bioinformatics analysis. $L A B, G M$ and VE drafted the paper, implementing contributions from all other authors. All authors read, corrected and approved the final manuscript.

Received: 2 December 2010 Accepted: 1 March 2011

Published: 1 March 2011

\section{References}

1. Fisher K, Phillips C: The ecology, epidemiology and virulence of Enterococcus. Microbiology 2009, 155:1749-1757.

2. Koch S, Hufnagel M, Theilacker C, Huebner J: Enterococcal infections: host response, therapeutic, and prophylactic possibilities. Vaccine 2004 22:822-830.

3. Klein G: Taxonomy, ecology and antibiotic resistance of enterococci from food and the gastro-intestinal tract. Int J Food Microbiol 2003, 88:123-131.

4. Kayser FH: Safety aspects of enterococci from the medical point of view. Int J Food Microbiol 2003, 88:255-262.

5. Paulsen IT, Banerjei L, Myers GS, Nelson KE, Seshadri R, Read TD, Fouts DE, Eisen JA, Gill SR, Heidelberg JF, et al: Role of mobile DNA in the evolution of vancomycin-resistant Enterococcus faecalis. Science 2003, 299:2071-2074.

6. Bourgogne A, Garsin DA, Qin X, Singh KV, Sillanpaa J, Yerrapragada S, Ding $Y$, Dugan-Rocha $S$, Buhay $C$, Shen $H$, et al: Large scale variation in Enterococcus faecalis illustrated by the genome analysis of strain OG1RF. Genome Biol 2008, 9:R110.

7. Domann E, Hain T, Ghai R, Billion A, Kuenne C, Zimmermann K, Chakraborty T: Comparative genomic analysis for the presence of potential enterococcal virulence factors in the probiotic Enterococcus faecalis strain Symbioflor 1. Int J Med Microbiol 2007, 297:533-539.

8. Lebreton F, Riboulet-Bisson E, Serror P, Sanguinetti M, Posteraro B, Torelli R, Hartke A, Auffray $Y$, Giard JC: ace, which encodes an adhesin in Enterococcus faecalis, is regulated by Ers and is involved in virulence. Infect Immun 2009, 77:2832-2839.

9. Coburn PS, Pillar CM, Jett BD, Haas W, Gilmore MS: Enterococcus faecalis senses target cells and in response expresses cytolysin. Science 2004, 306:2270-2272.

10. Engelbert M, Mylonakis E, Ausubel FM, Calderwood SB, Gilmore MS: Contribution of gelatinase, serine protease, and fsr to the pathogenesis of Enterococcus faecalis endophthalmitis. Infect Immun 2004, 72:3628-3633.

11. Coburn PS, Gilmore MS: The Enterococcus faecalis cytolysin: a novel toxin active against eukaryotic and prokaryotic cells. Cell Microbiol 2003, 5:661-669.

12. Zhou M, Boekhorst J, Francke C, Siezen RJ: LocateP: genome-scale subcellular-location predictor for bacterial proteins. BMC Bioinformatics 2008, 9:173.

13. Benachour A, Morin T, Hebert L, Budin-Verneuil A, Le Jeune A, Auffray Y, Pichereau $\mathrm{V}$ : Identification of secreted and surface proteins from Enterococcus faecalis. Can J Microbiol 2009, 55:967-974.

14. Cole JN, Ramirez RD, Currie BJ, Cordwell SJ, Djordjevic SP, Walker MJ: Surface analyses and immune reactivities of major cell wall-associated proteins of group a streptococcus. Infect Immun 2005, 73:3137-3146.

15. Antelmann $\mathrm{H}$, Tjalsma $\mathrm{H}$, Voigt $\mathrm{B}$, Ohlmeier S, Bron S, van Dijl JM, Hecker M: A proteomic view on genome-based signal peptide predictions. Genome Res 2001, 11:1484-1502.

16. Voigt B, Schweder T, Sibbald MJJB, Albrecht D, Ehrenreich A, Bernhardt J, Feesche J, Maurer KH, Gottschalk G, Dijl JMv, et al: The extracellular proteome of Bacillus licheniformis grown in different media and under different nutrient starvation conditions. Proteomics 2006, 6:268-281.
17. Mujahid S, Pechan T, Wang C: Improved solubilization of surface proteins from Listeria monocytogenes for 2-DE. Electrophoresis 2007, 28:3998-4007.

18. Dumas E, Desvaux M, Chambon C, Hebraud M: Insight into the core and variant exoproteomes of Listeria monocytogenes species by comparative subproteomic analysis. Proteomics 2009, 9:3136-3155.

19. Rodriguez-Ortega MJ, Norais N, Bensi G, Liberatori S, Capo S, Mora M, Scarselli M, Doro F, Ferrari G, Garaguso I, et al: Characterization and identification of vaccine candidate proteins through analysis of the group A Streptococcus surface proteome. Nat Biotechnol 2006, 24:191-197.

20. Rappsilber J, Ishihama Y, Mann M: Stop and go extraction tips for matrixassisted laser desorption/ionization, nanoelectrospray, and LC/MS sample pretreatment in proteomics. Analyt Chem 2003, 75:663-670.

21. Bendtsen JD, Nielsen $H$, von Heijne G, Brunak S: Improved prediction of signal peptides: SignalP 3.0. J Mol Biol 2004, 340:783-795.

22. Juncker AS, Willenbrock $H$, Von Heijne $G$, Brunak $S$, Nielsen $H$, Krogh $A$ : Prediction of lipoprotein signal peptides in Gram-negative bacteria. Protein Sci 2003, 12:1652-1662.

23. Krogh A, Larsson B, von Heijne G, Sonnhammer EL: Predicting transmembrane protein topology with a hidden Markov model: application to complete genomes. J Mol Biol 2001, 305:567-580.

24. Bendtsen JD, Jensen $\sqcup$, Blom N, von Heijne G, Brunak S: Feature-based prediction of non-classical and leaderless protein secretion. Protein Eng Des Sel 2004, 17:349-356.

25. Finn RD, Mistry J, Tate J, Coggill P, Heger A, Pollington JE, Gavin OL, Gunasekaran P, Ceric G, Forslund K, et al: The Pfam protein families database. Nucleic Acids Res 2010, 38:D211-222.

26. Tjalsma H, Lambooy L, Hermans PW, Swinkels DW: Shedding \& shaving: Disclosure of proteomic expressions on a bacterial face. Proteomics 2008, 1415-1428.

27. Rho JH, Wright DP, Christie DL, Clinch K, Furneaux RH, Roberton AM: A novel mechanism for desulfation of mucin: identification and cloning of a mucin-desulfating glycosidase (sulfoglycosidase) from Prevotella strain RS2. J Bacteriol 2005, 187:1543-1551.

28. Gardy JL, Laird MR, Chen F, Rey S, Walsh CJ, Ester M, Brinkman FSL: PSORTb v.2.0: Expanded prediction of bacterial protein subcellular localization and insights gained from comparative proteome analysis. Bioinformatics 2005, 21:617-623.

29. Bendtsen JD, Kiemer L, Fausboll A, Brunak S: Non-classical protein secretion in bacteria. BMC Microbiology 2005, 5:58.

30. Weaver KE, Clewell DB: Regulation of the $\mathrm{pAD} 1$ sex pheromone response in Enterococcus faecalis: effects of host strain and traA, traB, and C region mutants on expression of an $\mathrm{E}$ region pheromone-inducible lacZ fusion. J Bacteriol 1990, 172:2633-2641.

31. Chandler JR, Dunny GM: Enterococcal peptide sex pheromones: synthesis and control of biological activity. Peptides 2004, 25:1377-1388.

32. Schaumburg J, Diekmann O, Hagendorff P, Bergmann S, Rohde M, Hammerschmidt S, Jansch L, Wehland J, Karst U: The cell wall subproteome of Listeria monocytogenes. Proteomics 2004, 4:2991-3006.

33. Trost $\mathrm{M}$, Wehmhoner $\mathrm{D}$, Karst $\mathrm{U}$, Dieterich $\mathrm{G}$, Wehland J, Jansch L: Comparative proteome analysis of secretory proteins from pathogenic and nonpathogenic Listeria species. Proteomics 2005, 5:1544-1557.

34. Severin A, Nickbarg E, Wooters J, Quazi SA, Matsuka YV, Murphy E, Moutsatsos IK, Zagursky RJ, Olmsted SB: Proteomic analysis and identification of Streptococcus pyogenes surface-associated proteins. J Bacteriol 2007, 189:1514-1522.

35. Beck HC, Madsen SM, Glenting J, Petersen J, Israelsen H, Norrelykke MR, Antonsson M, Hansen AM: Proteomic analysis of cell surface-associated proteins from probiotic Lactobacillus plantarum. FEMS Microbiol Lett 2009, 297:61-66.

36. Sanchez B, Bressollier P, Chaignepain S, Schmitter JM, Urdaci MC: Identification of surface-associated proteins in the probiotic bacterium Lactobacillus rhamnosus GG. Int Dairy J 2009, 19:85-88.

37. Rodriguez-Ortega M, Luque I, Tarradas C, Barcena J: Overcoming function annotation errors in the Gram-positive pathogen Streptococcus suis by a proteomics-driven approach. BMC Genomics 2008, 9:588.

38. Tjalsma H, Lasonder E, Schöller-Guinard M, Swinkels DW: Shotgun immunoproteomics to identify disease-associated bacterial antigens: Application to human colon cancer. PROTEOMICS-Clin Appl 2007, 1:429-434.

39. Voland P, Weeks DL, Vaira D, Prinz C, Sachs G: Specific identification of three low molecular weight membrane-associated antigens of Helicobacter pylori. Aliment Pharmacol Ther 2002, 16:533-544. 
40. Ribeiro LA, Azevedo V, Le Loir Y, Oliveira SC, Dieye Y, Piard JC, Gruss A, Langella P: Production and targeting of the Brucella abortus antigen L7/ L12 in Lactococcus lactis: a first step towards food-grade live vaccines against brucellosis. Appl Environ Microbiol 2002, 68:910-916.

41. Mallick Al, Singha $H$, Chaudhuri $P$, Nadeem A, Khan SA, Dar KA, Owais M: Liposomised recombinant ribosomal L7/L12 protein protects BALB/C mice against Brucella abortus 544 infection. Vaccine 2007, 25:3692-36704.

42. Boleij A, Roelofs R, Schaeps RMJ, Schülin T, Glaser P, Swinkels DW, Kato I, Tjalsma H: Increased exposure to bacterial antigen RpL7/L12 in early stage colorectal cancer patients. Cancer 2010, 116:4014-4022.

43. Cantarel BL, Coutinho PM, Rancurel C, Bernard T, Lombard V, Henrissat B: The Carbohydrate-Active EnZymes database (CAZy): an expert resource for Glycogenomics. Nucleic Acids Res 2009, 37:D233-238.

44. Glycoside Hydrolase Family 25. [CAZypedia] [http://www.cazypedia.org/].

45. Mäkinen PL, Clewell DB, An F, Mäkinen KK: Purification and substrate specificity of a strongly hydrophobic extracellular metalloendopeptidase ("gelatinase") from Streptococcus faecalis (strain 0G1-10). J Biol Chem 1989, 264:3325-3334

46. Kayaoglu G, Ørstavik D: Virulence factors of Enterococcus faecalis: Relationship to endodontic disease. Crit Rev Oral Biol Med 2004, 15:308-320.

47. Mohamed JA, Huang DB: Biofilm formation by enterococci. J Med Microbiol 2007, 56:1581-1588.

48. Doro F, Liberatori S, Rodriguez-Ortega MJ, Rinaudo CD, Rosini R, Mora M, Scarselli M, Altindis E, D'Aurizio R, Stella M, et al: Surfome analysis as a fast track to vaccine discovery: Identification of a novel protective antigen for Group B Streptococcus hypervirulent strain $\mathrm{COH} 1$. Mol Cell Proteomics 2009, 8:1728-1737.

49. Sauvage E, Kerff F, Terrak M, Ayala JA, Charlier P: The penicillin-binding proteins: structure and role in peptidoglycan biosynthesis. FEMS Microbiol Rev 2008, 32:234-258.

50. Zapun A, Contreras-Martel C, Vernet T: Penicillin-binding proteins and $\beta$ lactam resistance. FEMS Microbiol Rev 2008, 32:361-385.

51. Mainardi JL, Legrand R, Arthur M, Schoot B, van Heijenoort J, Gutmann L: Novel mechanism of $\beta$-lactam resistance due to bypass of DDtranspeptidation in Enterococcus faecium. J Biol Chem 2000, 275:16490-16496.

52. Biarrotte-Sorin S, Hugonnet JE, Delfosse V, Mainardi JL, Gutmann L, Arthur M, Mayer C: Crystal structure of a novel beta-lactam-insensitive peptidoglycan transpeptidase. J Mol Biol 2006, 359:533-538.

53. Neuhaus FC, Baddiley J: A continuum of anionic charge: structures and functions of D-alanyl-teichoic acids in Gram-positive bacteria. Microbiol Mol Biol Rev 2003, 67:686-723.

54. Velez MP, Verhoeven TLA, Draing C, Von Aulock S, Pfitzenmaier M, Geyer A, Lambrichts I, Grangette C, Pot B, Vanderleyden J, et al: Functional analysis of D-alanylation of lipoteichoic acid in the probiotic strain Lactobacillus rhamnosus GG. Appl Environ Microbiol 2007, 73:3595-3604.

55. Fabretti F, Theilacker C, Baldassarri L, Kaczynski Z, Kropec A, Holst O, Huebner J: Alanine esters of enterococcal lipoteichoic acid play a role in biofilm formation and resistance to antimicrobial peptides. Infect Immun 2006, 74:4164-4171.

56. Debabov DV, Kiriukhin MY, Neuhaus FC: Biosynthesis of lipoteichoic acid in Lactobacillus rhamnosus: role of DItD in D-alanylation. J Bacterio/ 2000, 182:2855-2864.

57. Vebø HC, Snipen L, Nes IF, Brede DA: The transcriptome of the nosocomial pathogen Enterococcus faecalis V583 reveals adaptive responses to growth in blood. PLoS One 2009, 4:e7660.

58. Patti JM, Allen BL, McGavin MJ, Hook M: MSCRAMM-mediated adherence of microorganisms to host tissues. Annu Rev Microbiol 1994, 48:585-617.

59. Sillanpaa J, Xu Y, Nallapareddy SR, Murray BE, Hook M: A family of putative MSCRAMMs from Enterococcus faecalis. Microbiology 2004, 150:2069-2078.

60. Reed $L$, Koike M, Levitch ME, Leach FR: Studies on the nature and reactions of protein-bound lipoic acid. J Biol Chem 1958, 232:143-158.

61. Jiang Y, Cronan JE: Expression cloning and demonstration of Enterococcus faecalis lipoamidase (pyruvate dehydrogenase inactivase) as a Ser-Ser-Lys triad amidohydrolase. J Biol Chem 2005, 280:2244-2256.

62. Galli D, Friesenegger A, Wirth R: Transcriptional control of sexpheromone-inducible genes on plasmid pAD1 of Enterococcus faecalis and sequence analysis of a third structural gene for (pPD1-encoded) aggregation substance. Mol Microbiol 1992, 6:1297-1308.

63. Sanderson S, Campbell DJ, Shastri N: Identification of a CD4+ T cellstimulating antigen of pathogenic bacteria by expression cloning. J Exp Med 1995, 182:1751-1757.
64. Huycke MM, Moore D, Joyce W, Wise P, Shepard L, Kotake Y, Gilmore MS: Extracellular superoxide production by Enterococcus faecalis requires demethylmenaquinone and is attenuated by functional terminal quinol oxidases. Mol Microbiol 2001, 42:729-740.

65. Xingmin W, Mark MH: Extracellular superoxide production by Enterococcus faecalis promotes chromosomal instability in mammalian cells. Gastroenterology 2007, 132:551-561.

66. Huycke MM, Abrams V, Moore DR: Enterococcus faecalis produces extracellular superoxide and hydrogen peroxide that damages colonic epithelial cell DNA. Carcinogenesis 2002, 23:529-536.

67. Dreisbach A, Hempel K, Buist G, Hecker M, Becher D, van Dijl JM: Profiling the surfacome of Staphylococcus aureus. Proteomics 2010.

68. Ziebandt AK, Kusch H, Degner M, Jaglitz S, Sibbald MJJB, Arends JP, Chlebowicz MA, Albrecht D, Pantuček R, Doškar J, et al: Proteomics uncovers extreme heterogeneity in the Staphylococcus aureus exoproteome due to genomic plasticity and variant gene regulation. Proteomics 2010, 10:1634-1644.

doi:10.1186/1471-2164-12-135

Cite this article as: Bøhle et al:: Identification of surface proteins in Enterococcus faecalis V583. BMC Genomics 2011 12:135.

\section{Submit your next manuscript to BioMed Central and take full advantage of:}

- Convenient online submission

- Thorough peer review

- No space constraints or color figure charges

- Immediate publication on acceptance

- Inclusion in PubMed, CAS, Scopus and Google Scholar

- Research which is freely available for redistribution

Submit your manuscript at www.biomedcentral.com/submit
Ciomed Central 